\title{
Production Process Automation for Construction of Monolithic Buildings and Structures
}

\author{
Velichkin Vladimir \\ Department of Automation and Power Supply, Moscow State University of Civil Engineering (National Research University), Moscow, \\ Russia
}

Email address:

velichkinva@mgsu.ru

\section{To cite this article:}

Velichkin Vladimir, Production Process Automation for Construction of Monolithic Buildings and Structures. Journal of Civil, Construction and Environmental Engineering. Vol. 6, No. 3, 2021, pp. 87-91. doi: 10.11648/j.jccee.20210603.11

Received: March 31, 2021; Accepted: April 19, 2021; Published: April 29, 2021

\begin{abstract}
Article presents a scientific approach to creating a complex production process automation system for construction of monolithic buildings and structures (MBS). Specific features of systems with complex structure which present themselves in the way they function and by the interaction of local control systems within integrated system for production process automation were discovered. Justification is given to the structure of creation of local systems for automation of MBS construction processes and their functioning within interconnected complex control system. Model for optimal transportation of concrete mixture to the pouring site with sliding thermo-active formwork with hydraulic actuators is presented in the article. The model is integrated by parameters of physical and mechanical processes. Concept of production process automation for construction of MBS was outlined. The concept is implemented in accordance with specific operational and technological and IT support of integrated system for automated control. The greatest potential for increasing the rate of housing construction is possessed by the technology of monolithic housing construction. However, traditional methods of erecting monolithic structures are associated with increased labor intensity, a significant share of manual operations, and the lack of objective instrumental control of the quality of concrete work, which significantly affects the increase in the time and cost of construction. A radical solution to the problem of increasing the efficiency of monolithic housing construction technology is possible only through the integrated use of automation, robotization and microprocessor technology. A method and means have been developed for automating the processes of feeding, distributing, laying and compacting concrete mixture, which make it possible to fundamentally change not only the nature of the work of construction workers, but also its organization, productivity, quality and intellectual saturation. The technical requirements for the automated structures of switchgears are formulated, based on taking into account the specific technological conditions for the production of concrete works. A criterion is proposed and a methodology for choosing the optimal kinematic structure of an automated switchgear for the production of concrete works is developed. The problem of determining the geometric characteristics (the length of the links, the angles of rotation of the joints), the distribution booms for the given constructive and technological conditions of concreting has been solved.
\end{abstract}

Keywords: Cast-in-place Construction, Production Process, Concrete Mixture, Automation, Control Systems, Optimization Criteria, Supervisory Computer Control System, Information Signals, Control Function

\section{Introduction}

Monolithic construction of buildings and structures is a promising direction for the intensification of the construction industry and its volumes, according to most experts, will only grow in the coming years [1].

Increasing mass and altitude, changing configurations, as well as technological requirements for increased strength create the need to introduce new, more efficient technologies for construction of monolithic buildings and structures (MBS) by organic inclusion of control systems based on modern computing hardware and software [2].

MBS construction technology is identical to continuous technological process (TP), which provides continuous processes of preparation, transportation, distribution, and pouring of concrete mixture and with curing of concrete in 
sliding thermo-active formwork [3].

Such technological solution allows for maximum speeds in concrete works production, which leads to shorter MBS construction time [4].

Efficiency of transportation and distribution of concrete mixture (CM) in sliding thermo-active formwork, compaction and heating processes require creation and implementation of new technological solutions, with possibility of their automated control [5].

Analysis of technological processes of monolithic construction shows that when developing an integrated automation system, it is necessary to proceed from the features of available construction equipment and technological operations for their construction: technological continuity, technical means and solutions of automation, that provide optimization of qualitative parameters of the process $[5,6]$.

\section{Method}

The automation system should reflect integrated nature of management in its structure and algorithms, which implies merger of the operational management of individual technological process operations from construction of the structure as a whole.

Such integrated system should have capability to control lover level units with ways to coordinate individual local subsystems.

Local automation systems, i.e. control units of the lower level, control the process itself in real time. At this level, individual subprocesses are optimized, and the progress of operations is monitored.

The proposed ideology defines the general principles that should be the basis for the formation of a specific automated structure of the technological process for building objects from monolithic reinforced concrete. It defines a set of specific requirements that must be met by both technological process and associated automation system. [9]

\section{Discussion}

There are practical and theoretical needs for development of a set of methods and means for effective control of the quality selection of concrete mix, for technological characteristics of the subsequent operations of transportation, distribution, pouring, compaction and curing of $\mathrm{CM}$ in sliding thermo-active formwork.

The presence of controlled characteristics of source materials and change in homogeneity of the concrete mixture during transportation, characterized by random deviations, makes it viable to use a multi-level control system (Figure 1).

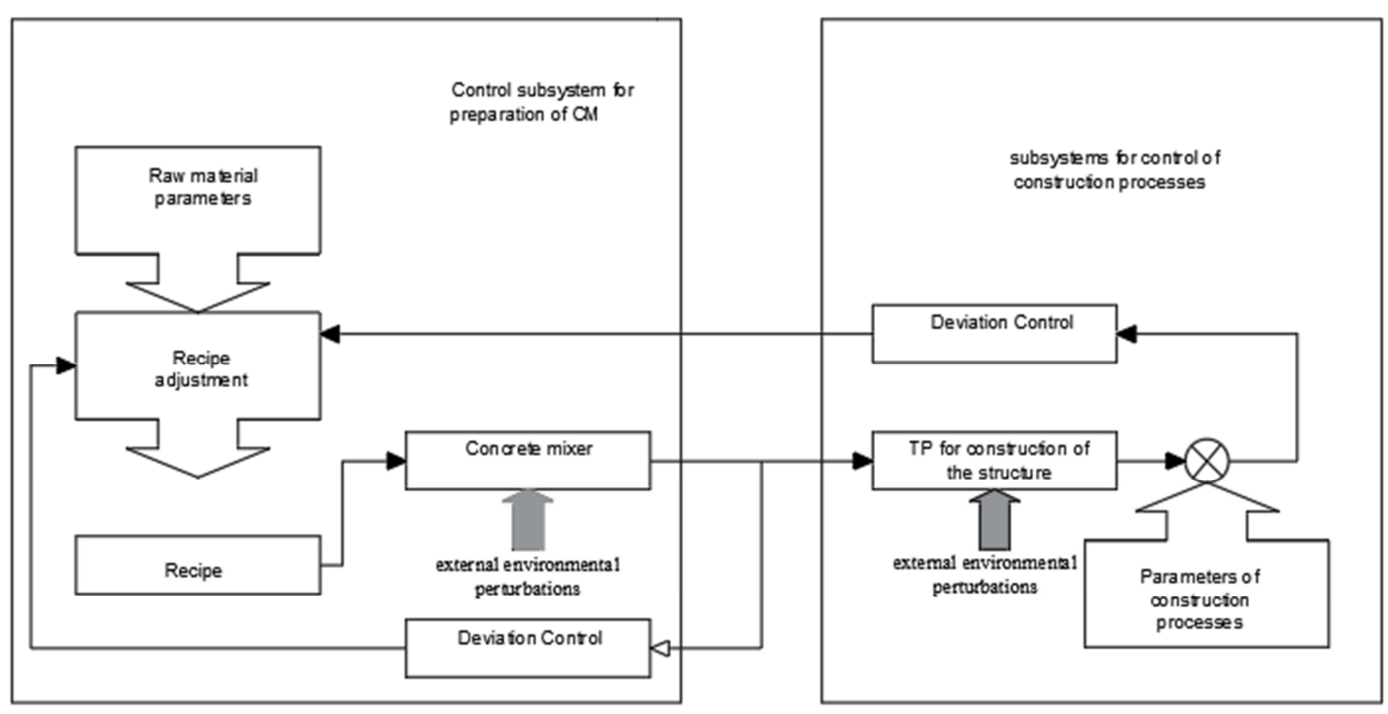

Figure 1. MBS construction control system.

When managing complex systems, division of control functions on a hierarchical basis is unavoidable. Hierarchical elements at the upper levels influence the process flow through control of the device of the lower level, defining for them setting action through static optimization methods. The latter are implemented automatically by local control systems. $[7,8]$

The tasks of static optimization and regulation are presented by a set of methods and means for solution. However, regular correction of the optimization criterion value and adjustment of the regulator depending on changing technological parameters with discreteness, determined by the completeness of information about the deviation of the action result of the process from its optimal value, is necessary. The interrelation of such tasks can be realized quite organically only in multilevel hierarchical control systems. [10]

Allocation of levels in the control system is determined by the amount of information received at this level, and therefore by frequency of its use for control at the lower levels of the system. Essential in such a system is the frequency with which the upper levels of the hierarchy change the values of the adjusted parameters of the lower level elements, which increases as the hierarchy moves from 
top to bottom. This property makes it possible to combine the tasks of static optimization and automatic control, which are solved at different levels of the hierarchy. Therefore, corrective controls are applied at the end of each cycle, during which you can get comprehensive information about the process. Such a principle of real-time control can be implemented only in a multi-level hierarchical system, when a continuous control process is conditionally divided into discrete intervals with a given frequency of application of corrective actions. [11]

Optimization is carried out based on the amount of information sufficient for the qualitative characterization of the process. Having identified the amount of information sufficient for an objective assessment of the TP progress, the settings of the local automation systems are corrected. Stated principles of structuring an automated control system allow to present a functional diagram in the form of a three-level hierarchy (Figure 2).

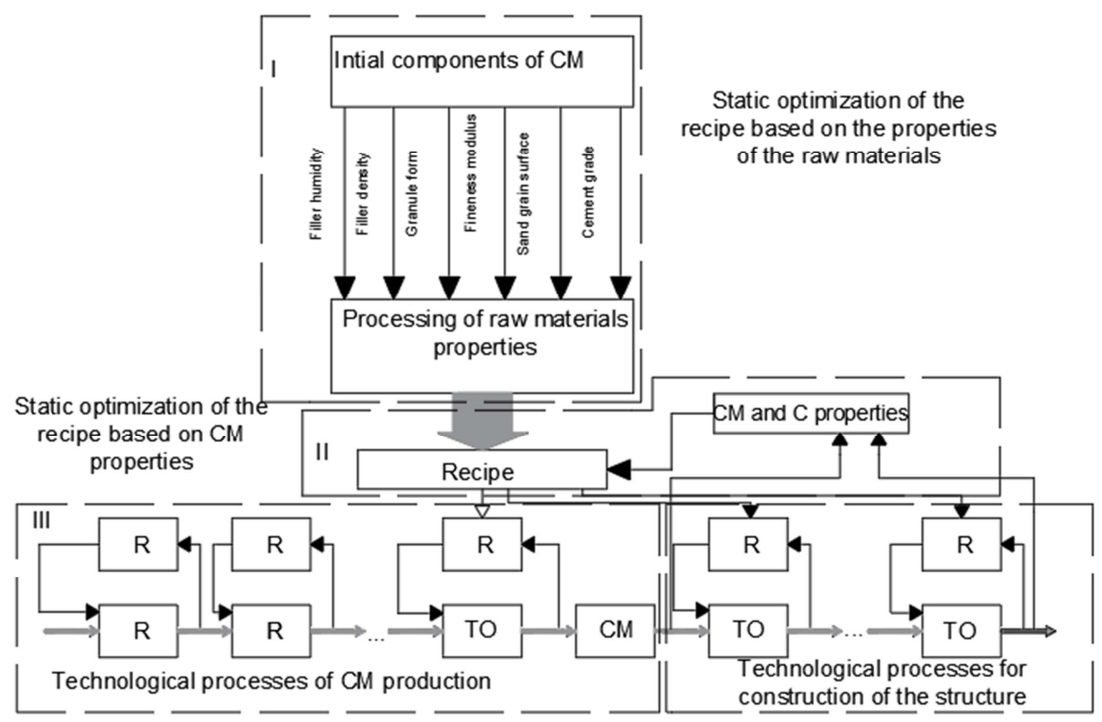

R-regulator; $\mathrm{TO}$ - technological operation; $\mathrm{CM}$ - concrete mixture; $\mathrm{C}$ - concrete

Figure 2. Functional diagram of a three-level automation system.

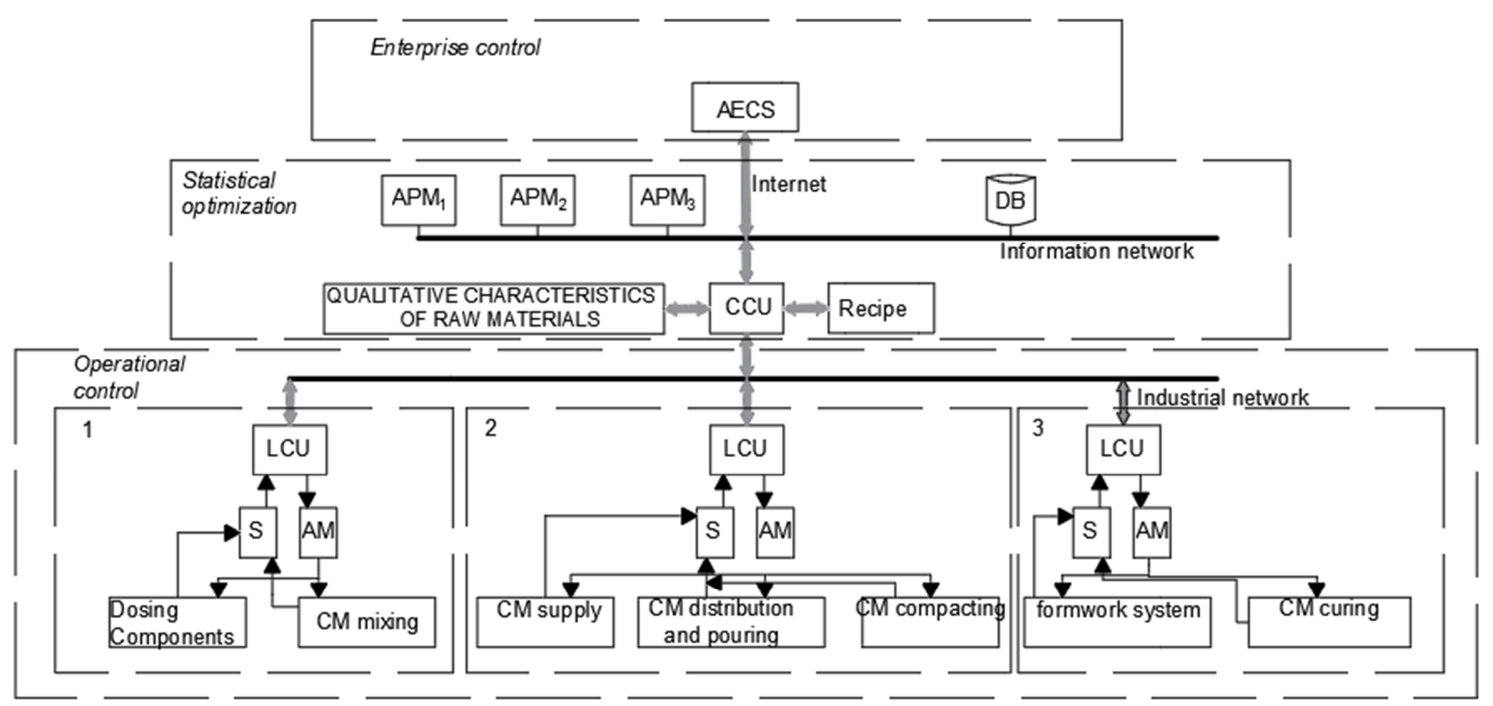

Figure 3. A generalized block diagram of an integrated automation system for TP of a monolithic structure construction.

1- control subsystem for CM preparation processor; 2- control subsystem for supply, pouring and compaction of CM; 3- control subsystems for lifting formwork and CM curing; S- sensors; AM- actuation mechanisms; LCU- local control units, CCU- Central control Unit; APM- computer workstation; DBdatabase; AECS- automated enterprise control system

The main task of the designed control system should be to match the external environmental perturbations with the variety of reactions of the control part. The most important structural principle in the design of hierarchical systems is the intellectual algorithm underlying it, called functional hierarchy, in the form of three hierarchically coordinated levels: decision, training, and self-organization.

Local controlled objects of the lower level form a technological network, a quantitative change in the complexity of which leads to a qualitative change in the 
properties of the complex control system. $[12,13]$

General provisions for formation of an automated control system for continuous technological processes should be based on the methodology determined by the features of existing technologies for construction of monolithic reinforced concrete structures. The principles underlying automated technology of the processes for preparation, supply, distribution, pouring and compacting a concrete mix during construction of a monolithic structure can be implemented as an integrated automation system, generalized structure of which is shown in Figure 3.

The structure of the integrated automation system consists of two main levels: operational management of individual operations of the technological process and static optimization, information from which goes to the topmost level - enterprise management.

At the lower operational level of the integrated control system there are sensors (S) for collecting information and actuating mechanisms (AM) that directly change the state of the technological equipment. Information from the sensors goes to the local control units (LCU), which issue control actions to the actuating mechanisms.

The system assumes optimization of the concrete mix recipe based on the information on the quality of raw materials and intermediate quality characteristics of $\mathrm{CM}$ and hardening concrete obtained over a defined period of time. LCU collects, preprocesses and stores information about the state of the equipment and parameters of the technological process, automatically controls, regulates and executes commands from the level of operational control and statistical optimization, self-diagnoses software operation and state of local control units, exchange of information with control points.

An important element in the development of an integrated automation system for technological processes in the monolithic buildings and structures construction is the organization of a continuous process with the help of local automated control systems for supply, pouring and compacting concrete mix $(\mathrm{CM})$ into a sliding thermo-active formwork.

Regulatory requirements of the $\mathrm{CM}$ transportation process with concrete pumps determines usage of hydraulic actuators (Figure 4). They have great reliability in operation, a smooth nature of regulation with a large range of movement, a large switching force, high sensitivity and speed.

Considering the change in movement speed $V_{\amalg}$ of the hydraulic power cylinder rod $(\mathrm{HC}) \mathrm{d}\left(\mathrm{V}_{\mathrm{W}}\right) / \mathrm{dt}=\mathrm{d}\left(\Delta \mathrm{V}_{\mathrm{W}}\right) / \mathrm{dt}$ the linear differential equation of the hydraulic drive of the concrete pump, considering the load by $\mathrm{CM}$, transported through the pipeline, will be:

$$
\frac{\mathrm{m}_{\amalg} \mathrm{F}_{0} * \mathrm{~d}^{2}\left(\Delta \mathrm{V}_{\amalg}\right)}{2 * \mathrm{E}_{\Pi} \mathrm{A}_{\mathrm{AK}} * \mathrm{dt}^{2}}+\frac{\mathrm{m}_{\amalg} \mathrm{K}_{\mathrm{QP}} * \mathrm{~d}\left(\Delta \mathrm{V}_{\amalg}\right)}{\mathrm{A}_{\mathrm{AK}}^{2} * \mathrm{dt}}+\Delta \mathrm{V}_{\amalg}=\frac{\mathrm{K}_{\mathrm{VX}}}{\mathrm{A}_{\mathrm{AK}}} * \Delta \mathrm{X}_{\amalg}
$$

Or

$$
\mathrm{T}_{1} \mathrm{~T}_{2} * \frac{\mathrm{d}^{2}\left(\Delta \mathrm{V}_{\amalg}\right)}{\mathrm{dt}^{2}}+\mathrm{T}_{2} * \frac{\mathrm{d}\left(\Delta \mathrm{V}_{\mathrm{W}}\right)}{\mathrm{dt}}+\Delta \mathrm{V}_{\mathrm{W}}=\mathrm{K}_{\mathrm{VX}} \Delta \mathrm{X}_{\amalg}
$$

where $\mathrm{m}_{\amalg}-\mathrm{HC}$ piston rod mass, $\mathrm{F}_{0}-\mathrm{HC}$ cavity volume; $\mathrm{E}_{\Pi}$ - adjusted value of the volumetric modulus of elasticity of $\mathrm{CM} ; \mathrm{A}_{\mathrm{AK}}-\mathrm{CM}$ flow self-excited oscillations amplitude upon passing length $\mathrm{X}_{\amalg}$ in the cavity of $\mathrm{HC} ; \mathrm{K}_{\mathrm{QP}}-$ mass amplification ratio for $\mathrm{CM}$ flow; $\mathrm{K}_{\mathrm{VX}}=\mathrm{Q}_{\mathrm{PX}} / \mathrm{A}_{\mathrm{AK}}-$ speed amplification ratio for $\mathrm{CM}$ passing through $\mathrm{HC} ; \mathrm{T}_{1}=\mathrm{F}_{0} / 2$ $\mathrm{E}_{\Pi} \mathrm{K}_{\mathrm{QP}}$ - time response, taking into account non-uniformity (compressibility) of $\mathrm{CM}$ passage through $\mathrm{HC}$; $\mathrm{T}_{2}=\mathrm{m}_{\amalg} \mathrm{K}_{\mathrm{QP}} / \mathrm{FA}^{2}{ }_{\mathrm{AK}}$ - time response, considering load inertia; $\mathrm{Q}_{\mathrm{P}}-$ bulk density; $\mathrm{P}=\mathrm{f}\left(\mathrm{X}_{\amalg}\right)-\mathrm{CM}$ mass, which passes through $\mathrm{HC}$ per unit of length $\mathrm{X}_{\amalg}=\mathrm{f}(\mathrm{t}) ; \mathrm{K}_{\mathrm{Q}}-\mathrm{CM}$ consumption ratio for formwork loading.

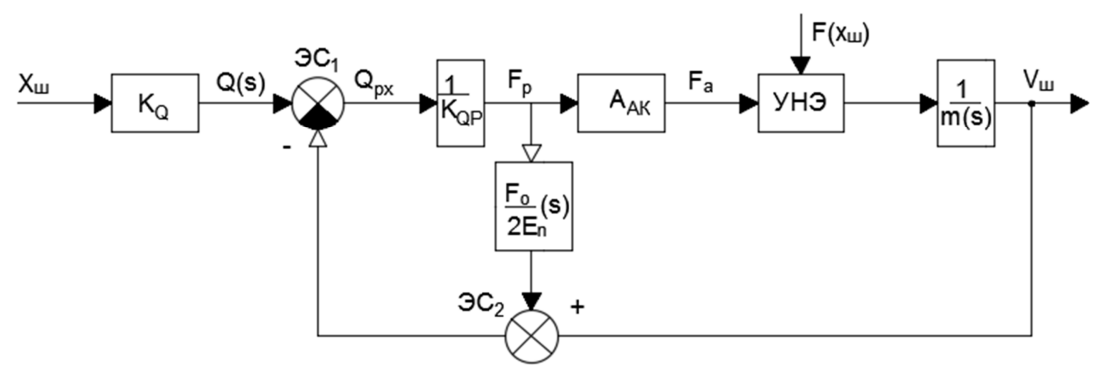

Figure 4. Structural diagram of the hydraulic drive model for concrete pump.

The resistance force $\mathrm{Fc}$ varies widely and is a complex indicator that depends on the magnitude of $\mathrm{A}_{\mathrm{AK}}$, change in loading mass $\mathrm{Q}(\mathrm{S})$ and the driving force $\mathrm{Fp}$, which moves the mass of CM in the concrete pipe. [14]

The mathematical model of the hydraulic pipe takes into account the state of maximum load of the concrete pump drive when the active force Fp of the CM displacement through the concrete pipe is equal in magnitude to the resistance force $(\mathrm{Fp}=\mathrm{Fc})$. With inequality $\mathrm{Fp} \neq \mathrm{Fc}$ from the values of $\mathrm{A}_{\mathrm{AK}}$ and $\mathrm{Q}(\mathrm{S})$, the hydraulic drive model should include in the block diagram a nonlinear unit (NU) with a nonlinear static characteristic $\mathrm{F}\left(\mathrm{x}_{\mathrm{II}}\right)$.

Modern methods and principles of automation of complexly-structured technological processes are implemented on the basis of specialized supervisory computer control systems, including programmable logic controllers (PLC), intelligent input-output modules, etc. Examples of such software and hardware systems are hardware and software automation products from Tecon, Siemens, AllenBradley, SchneiderElectric, MZTA, and others, which offer PLCs, I/ O 
modules, and a range of intelligent devices with high communication and computing capabilities. $[15,16]$

Communication between local controllers, sensors, actuating mechanisms and the central control device is usually carried out using specialized industrial networks (Modbus, HART, Device NET, etc.), as it allows to receive information from the primary measuring elements.

For the organization of communication between the central computing unit, computer work stations of operators, database and other objects of operational control and static optimization, it is possible to use information networks like Ethernet.

Modern design and management software systems for automated process control systems such as SCADA make it possible to organize a complete interface between different levels. Thus, the principle of integration of operational management and static optimization levels is implemented.

\section{Conclusion}

The proposed concept of automation in relation to the TP of monolithic industrial facilities construction is implemented in accordance with a specific operational, technological, and informative-technical content of a complex automated control system.

Effective functioning of TP with complexly subordinate units in the form of local control units is possible only with the help of complex automation, which should provide a structural and functional connection of elements.

With the use of computer technology, the concept of creating automation systems for technological processes is changing, thereby determining the maximum integration of technology, hardware and control modes. This allows realtime control algorithms to be implemented with a high degree of complexity.

Not only the structure of the control system is changing, which acquires the properties of multilevel and hierarchy, but also the nature of the interaction of individual technological devices.

Given theoretical substantiations allow us to solve relevant problem of synthesizing coherent hierarchical (local) control systems for continuous technological processes of MBS construction, ensuring the implementation of substantially new ways to improve the basic indicators of the construction industry.

\section{References}

[1] Evdokimov N. I., Matskevich A. F., Sytnik B. C. Technology of monolithic concrete and reinforced concrete: Textbook for construction universities. Moscow: Higher School, 2015. 335 e.: ill.
[2] Guide to the construction of formwork and the production of formwork works / Center, n. i. i project, experiment, Institute of organization, mechanization and technical assistance to the construction of Gosstroy of the USSR. - M.: Stroyizdat, 2017. -501 E.: il.

[3] Afanasyev A. A. Intensification of work in the construction of buildings and structures made of monolithic reinforced concrete, - M.: Stroyizdat, 2015. -384 p.

[4] Technology, mechanization and automation of construction: Studies for higher education institutions on spec. "Economics and management in construction"/ S. S. Ataev, V. A. Bondarik, I. N. Gromov, etc.; Edited by S. S. Ataev, S. Ya. Lutsky. M.: Higher School of Economics, 2018 - 592 e.: ill.

[5] Evdokimov V. A. Mechanization and automation of construction production. L.: Stroyizdat, 2017.

[6] Afanasyev A. A. Concrete works: Textbook for professional training of workers on the ave., - 2nd ed., reprint. and add. M.: Higher School, 2014, - 288 e.: ill.

[7] Manual for laying concrete mixes with concrete pumping installations / Center, n. i. i. proekt, experimentalinstv, in-t organizatsii, mechanizatsii i tekhnicheskoi pomoshchey stroitel'noi Gosstroya SSSR. - M.: Stroyizdat, 2018. - 144 e.: il

[8] Gorin V. A., "Civil buildings of mass construction", educational literature, 2013.

[9] Vilman Y. A., " Technology of construction processes and construction of buildings. Modern progressive methods", educational literature, 2014.

[10] Anpilov S. M., "Technology of construction of buildings and structures made of monolithic reinforced concrete", educational literature, 2010.

[11] Marsov V. I., Mintsaev M. Sh., Askhabov I. B. Monolithic construction technology using fixed formwork. // Bulletin of MADI (GTU). - M.: approx. 2 (17), 2009, pp. 38-40.

[12] Mintsaev M. S. h. Features of automation of concrete work in monolithic housing construction. // Bulletin of MADI (GTU), 2003. S. 120-126.

[13] Bulgakov A. G., Parshin D. Ya. Sliding formwork management in the construction of monolithic buildings. M. Mechanization of construction, 1997, No. 12, p. 15-18.

[14] Gudikov G. G. Automatic control of the accuracy of the construction of monolithic buildings and structures. $\mathrm{M}$. MDITN, 2008, pp. 98-102.

[15] Khodykin V. V., Tikhonov A. F. Automation of technological processes for the production of concrete works in monolithic housing construction. Collection of NRU MGSU "Automation of technological processes, machines and equipment", 1999, p. $53-56$

[16] Plotnikov N. M., Khodykin V. V. Automation of monolithic housing construction based on microwave control devices for the processes of laying and compacting concrete mixture. M. Automation and modern technologies, 1996, no. 10, p. 2-5. 